\title{
Simultaneous estimation of Aliskiren hemifumarate and Hydrochlorothiazide in combined Tablet Formulation by Simultaneous equation, Absorbance ratio and First derivative Spectroscopic Methods
}

\author{
Ashim Kumar Sen ${ }^{*}$, Dhanya B Sen, Rajesh A Maheshwari, Ramachandran Balaraman, Avinash K Seth \\ Department of Pharmacy, Sumandeep Vidyapeeth University, Piparia, Waghodia, Vadodara-391760, Gujarat, India.
}

\begin{tabular}{l}
\hline ARTICLE INFO \\
\hline Article history: \\
Received on: 07/10/2015 \\
Revised on: 06/01/2016 \\
Accepted on: 11/03/2016 \\
Available online: $28 / 07 / 2016$ \\
\hline Key words: \\
Aliskiren hemifumarate, \\
hydrochlorothiazide, \\
simultaneous equation, \\
absorbance ratio, first \\
derivative spectroscopic \\
methods, tablet formulation.
\end{tabular}

\begin{abstract}
Three simple, sensitive, precise and accurate UV-spectroscopic methods namely simultaneous equation, absorbance ratio and first derivative (zero crossing) spectroscopic methods were developed and validated for simultaneous determination of aliskiren hemifumarate and hydrochlorothiazide in tablet dosage form. Simultaneous equation method was based on the measurement of absorbance at 271 and $280 \mathrm{~nm}$ for both the drugs. In absorbance ratio method 255 and $271 \mathrm{~nm}$ was used for the quantification of aliskiren hemifumarate and hydrochlorothiazide. First derivative method was involved in the conversion of UV-spectra in to first derivative spectra and measurement of first derivative signal at 241 and $280.2 \mathrm{~nm}$ for aliskiren hemifumarate and hydrochlorothiazide, respectively using $2 \mathrm{~nm}$ as wavelength interval $(\Delta \lambda)$ and 1 as scaling factor. Methods were validated as per ICH guidelines including parameters viz., specificity, linearity and range, precision, accuracy, limit of detection and quantification. All the methods were found to be linear in the concentration range of 6-300 $\mu \mathrm{g} / \mathrm{ml}$ for aliskiren hemifumarate and $0.5-25 \mu \mathrm{g} / \mathrm{ml}$ for hydrochlorothiazide. Results of validation studies follows ICH guideline acceptable limits. Methods were compared based on the assay results obtained using one-way ANOVA followed by Bonferroni multiple comparison tests (95\% confidence level) as appropriate using computer based fitting program (Prism, Graphpad version 5, Graphpad Software Inc). Results of statistical analysis revealed that there was no significant difference between simultaneous equation, absorbance ratio and first derivative method. Developed methods were simple, rapid, highly sensitive and cost effective as compared to existing methods and can be useful for simultaneous estimation of aliskiren hemifumarate and hydrochlorothiazide in commercial tablet formulation for routine quality control.
\end{abstract}

\section{INTRODUCTION}

Aliskiren hemifumarate (ALI) is chemically described as $\quad(2 \mathrm{~S}, 4 \mathrm{~S}, 5 \mathrm{~S}, 7 \mathrm{~S})-\mathrm{N}-\quad$ (2-methylpropyl) 5amino-4-hydroxy2,7diisopropyl-8-[4-methoxy-3-(3-methoxypropoxy)- phenyl]octamide hemifumarate, a renin inhibitor, widely used for the treatment of essential hypertension. Hydrochlorothiazide (HCT), chemically 6-chloro -3,4-dihydro-2H-1,2,4-benzothiadiazine-7sulfomide 1,1-dioxide is a thiazide diuretic used in the

\footnotetext{
* Corresponding Author Ashim Kumar Sen, Department of Pharmacy, Sumandeep Vidyapeeth University, Piparia, Waghodia, Vadodara-391760, Gujarat, India. Email:ashims01@gmail.com
}

management of hypertension. Chemical structures of both the drugs are shown in Figure 1. Hypertension is one of the most common and powerful risk factors for cardiovascular diseases. Blood pressure control is prerequisite for the management of cardiovascular diseases and complications. More than one medication is required for the effective control of blood pressure of the cardiovascular patient.

ALI is the first representative of a new class of non peptide, low molecular weight; orally active transition state renin inhibitor shows effective control of blood pressure and cardiovascular diseases when combined with HCT, a thiazide diuretic (Martindale, 2009; The Merck Index, 2001; Indian Pharmacopoeia, 2007; Sen et al., 2015). 


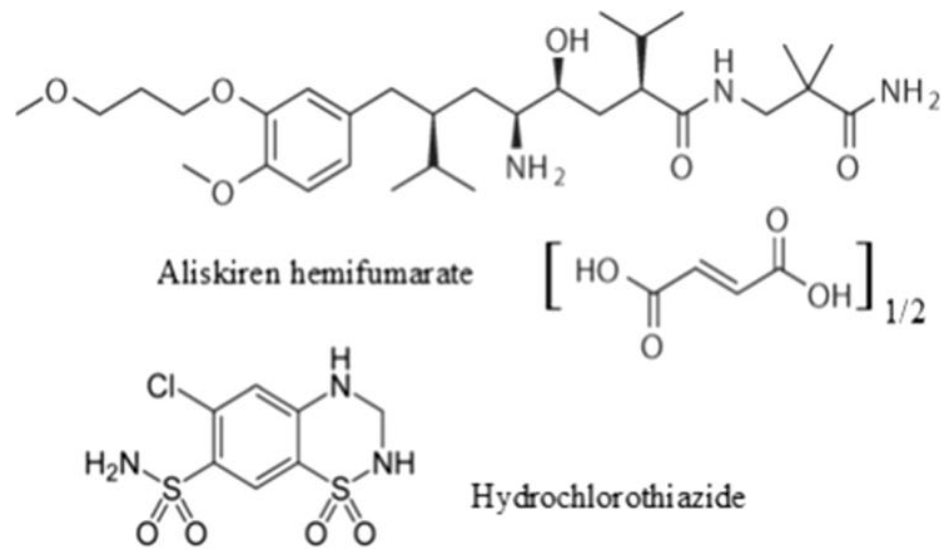

Fig. 1: Chemical structures of ALI (aliskiren hemifumarate) and HCT (hydrochlorothiazide).

Literature survey revealed various analytical methods for the determination of ALI along with HCT in laboratory prepared mixture and combined tablet dosage form using UVspectrophotometry (Ezzeldin et al., 2013; Ezzeldin et al., 2013; Patel et al., 2014), HPLC (Sangoi et al., 2011; Karvelis et al., 2014; Belal et al., 2013; Dimitrios et al., 2014; Swamy et al., 2012), MEKC (Sangoi et al., 2011) and electrophoresis (Salim et al., 2014).

There was scope for more sensitive, reliable and statistically proven alternative methods for the determination of ALI and HCT in combined tablet dosage form using simple UVspectroscopic methods compared to existing methods. Therefore, aim of the present work was to develop and validate some simpler, sensitive, precise, accurate and cost effective UV-spectroscopic methods as compared to existing methods for the determination of ALI and HCT in commercial tablet formulation (Rasilez $\mathrm{HCT}^{\circledR}$ ). The advantages of proposed methods are as follows; methods describe standard and sample preparation procedure based on the form of analytes under investigation, i.e. aliskiren $(13.26 \mathrm{mg}$ of aliskiren hemifumarate is equivalent to $12 \mathrm{mg}$ of aliskiren); wide concentration range with high sensitivity; all the developed methods were validated as per ICH guidelines.

\section{MATERIALS AND METHODS}

\section{Chemicals and Reagents}

ALI reference standard was provided as gift sample by Jubilant Life Sciences Ltd., Noida, Uttar Pradesh, India and HCT was obtained from Glenmark Pharmaceuticals Ltd., Mumbai, Maharashtra, India. Rasilez HCT $^{\circledR}$ tablets containing $300 \mathrm{mg}$ of ALI along with $25 \mathrm{mg}$ of HCT were procured from commercial sources. Methanol used was of AR grade and procured from Loba Chemie Pvt. Ltd., Mumbai, India.

\section{Apparatus}

Shimadzu double beam UV-visible spectrophotometer (UV-1800, UV Probe, Shimadzu Corporation, Kyoto, Japan) along with matched quartz cell of $1 \mathrm{~cm}$ path length was used throughout the experiment. Highly sensitive electronic balance Adventurer Pro AVG264C, Ohaus Corporation, Pine Brook, NJ, USA was used for weighing purpose.

\section{Preparation of Standard Solution}

Stock solution of ALI and HCT were prepared by weighing accurately $11.05 \mathrm{mg}$ of ALI (11.05 mg of ALI is equivalent to $10 \mathrm{mg}$ of aliskiren) and $10 \mathrm{mg}$ of HCT standard drug which was then transferred to a $10 \mathrm{ml}$ volumetric flask separately and diluted to $10 \mathrm{ml}$ with methanol to get the concentration of the drugs $1000 \mu \mathrm{g} / \mathrm{ml}$. Further dilutions were made to get desired concentration with methanol.

\section{Procedure}

\section{Simultaneous Equation and Absorbance Ratio Method}

Standard stock solutions of ALI and HCT were further diluted separately with methanol to get the drug solutions containing $60 \mu \mathrm{g} / \mathrm{ml}$ of ALI and $5 \mu \mathrm{g} / \mathrm{ml}$ of HCT, respectively. Both the solutions were scanned in the UV region $(200-400 \mathrm{~nm})$ and spectra were recorded. Based on the spectral pattern, SE (simultaneous equation) and AR (absorbance ratio) method (Beckett and Stenlake, 2005) was selected for the estimation of both the drugs. From the overlain spectra (Figure 2), $271 \mathrm{~nm}\left(\lambda_{\max }\right.$ of HCT) and $280 \mathrm{~nm}\left(\lambda_{\max }\right.$ of ALI) were selected for SE method. For AR method $255 \mathrm{~nm}$ (isobestic point) and $271 \mathrm{~nm}\left(\lambda_{\max }\right.$ of HCT) were selected, which showed good linearity and hence used for simultaneous estimation. Different concentrations of ALI (6$300 \mu \mathrm{g} / \mathrm{ml})$ and $\mathrm{HCT}(0.5-25 \mu \mathrm{g} / \mathrm{ml})$ were prepared from respective stock solutions. The absorbances were noted at 271 and $280 \mathrm{~nm}$ for SE; 255 and $271 \mathrm{~nm}$ for AR method. The absorptivity values were calculated for ALI and HCT at their respective wavelengths by using following formula:

Absorptivity $=$ absorbance $/$ concentration $(\mathrm{gm} / 100 \mathrm{ml})$ Absorptivity value of individual solution was calculated and average absorptivity value (Table 1) at specific wavelength of particular drug was used for calculating concentration of drugs. 


\section{First Derivative (zero crossing) Method}

The normal UV-spectra of ALI and HCT were converted into first and second derivative spectra. Based on the spectral pattern and zero crossing points, first DR (derivative spectroscopic) method was selected for the study. First derivative spectra showed typical zero-crossing points at $280.20 \mathrm{~nm}$ for ALI and $241 \mathrm{~nm}$ for HCT using $2 \mathrm{~nm}$ as wavelength interval $(\Delta \lambda)$ and 1 as scaling factor. From the overlain spectra, $241 \mathrm{~nm}$ and 280.20 $\mathrm{nm}$ were selected for further studies (Figure 3). Calibration curve was plotted for both ALI and HCT in the range of 6 to $300 \mu \mathrm{g} / \mathrm{ml}$ and 0.5 to $25 \mu \mathrm{g} / \mathrm{ml}$, respectively. Results were subjected to regression analysis by least square method to calculate the values of slope, intercept and correlation coefficient.

\section{Preparation of Sample Solution}

Twenty tablets of Rasilez HCT ${ }^{\circledR}$ (300 mg of ALI and 25 mg of HCT) were accurately weighed and average weight was calculated. All the tablets were crushed to fine powder and quantity equivalent to $60 \mathrm{mg}$ of ALI and $5 \mathrm{mg}$ of HCT were weighed and transferred to a $50 \mathrm{ml}$ volumetric flask. Flask was vortexed after adding $30 \mathrm{ml}$ of methanol and shaken for 10 minutes and volume was made up to the mark with methanol. Contents were filtered through whatman filter paper no 41 and suitable aliquots were prepared to get desired concentrations (eg. ALI $120 \mu \mathrm{g} / \mathrm{ml}$ and HCT $10 \mu \mathrm{g} / \mathrm{ml}$ ).

\section{Analysis of Sample Solution \\ Simultaneous Equation Method}

After scanning the sample solution (formulation) between 200 to $400 \mathrm{~nm}$, absorbances were noted at 271 and 280 $\mathrm{nm}$. The unknown concentration of drugs in sample solution was estimated by solving SE using following formula [Sen et al., 2015]:

$$
C x=\frac{A_{2} a_{y 1}-A_{1} a_{y 2}}{a_{x 2} a_{y 1}-a_{x 1} a_{y 2}} \quad C y=\frac{A_{1} a_{x 2}-A_{2} a_{x 1}}{a_{x 2} a_{y 1}-a_{x 1} a_{y 2}}
$$

Where $C x$ and $C y$ are the concentrations of ALI and HCT, $a_{1}$ and $\mathrm{ax}_{2}$ are absorptivities of ALI at 271 and $280 \mathrm{~nm}$, respectively. ay and $\mathrm{ay}_{2}$ are absorptivities of HCT at 271 and $280 \mathrm{~nm}$, respectively. $A_{1}$ and $A_{2}$ are the absorbances of sample solution at 271 and 280 $\mathrm{nm}$.

\section{Absorbance Ratio Method}

The unknown concentration of drugs in sample solution was estimated by AR method using following formula:

$$
\mathrm{Cx}=\frac{Q m-Q y}{\mathrm{Qx}-\mathrm{Qy}} \times \frac{\mathrm{A} 1}{a x 1} \quad \mathrm{Cy}=\frac{Q m-Q x}{\mathrm{Qy}-\mathrm{Qx}} \times \frac{\mathrm{A} 1}{a y 1}
$$

Where, $\mathrm{ax}_{1}$ and $\mathrm{ax}_{2}$ are absorptivities of ALI at 255 and $271 \mathrm{~nm}$, respectively. ay $\mathrm{y}_{1}$ and $\mathrm{ay}_{2}$ are absorptivities of $\mathrm{HCT}$ at 255 and 271 $\mathrm{nm}$, respectively. $\mathrm{A}_{1}$ and $\mathrm{A}_{2}$ are the absorbances of sample solution at 255 and $271 \mathrm{~nm}$. Cx and $\mathrm{Cy}$ are the concentrations of ALI and HCT, respectively in sample solution.

$$
Q m=\frac{A 2}{A 1} \quad Q x=\frac{a x 2}{a x 1} \quad Q y=\frac{a y 2}{a y 1}
$$

\section{First Derivative (zero crossing) Method}

Sample solution was scanned in the UV region (200-400 $\mathrm{nm}$ ) and spectrum was recorded and converted into their $1^{\text {st }}$ derivative spectra and amplitude was measured at 241 and 280.20 $\mathrm{nm}$. The unknown concentration of drugs in sample solution was estimated by using regression equation.

\section{Validation of Spectroscopic Methods}

The developed methods were validated in accordance with "International Conference on Harmonization" guidelines [ICH, 2005] for validation of analytical procedures.

\section{Specificity}

To check the interference between tablet excipients used in the marketed formulation and drug substance, specificity study was performed. Tablet excipients were mixed in proportion (as per marketed formulation) and diluted using methanol and filtered through whatman filter paper no 41. All the solutions (Placebo and standard) were scanned in the UV region and compared with standard spectra to evaluate the interference between excipients and drugs.

\section{Linearity and Range}

Linearity and range of all the three methods were checked by analyzing all the standard solutions separately, containing ALI $(6,12,60,120,180,240$ and $300 \mu \mathrm{g} / \mathrm{ml})$ and HCT $(0.5,1,5,10,15,20$ and $25 \mu \mathrm{g} / \mathrm{ml})$ in methanol and absorbances were measured at 271 and $280 \mathrm{~nm}$ for SE method; 255 and $271 \mathrm{~nm}$ for AR method; 241 and $280.20 \mathrm{~nm}$ for $1^{\text {st }}$ DR method. Calibration graphs were plotted using absorbances of standard drug solutions versus concentration for SE and AR method; $1^{\text {st }}$ derivative signal of standard drug solutions versus concentration for DR method. Regression analysis was performed by least squares method to calculate the values of slope, intercept and correlation coefficient.

\section{Precision}

Precision of the methods were checked by carrying out repeatability, intra-day and inter-day precision. Repeatability of the methods were checked by analyzing sample solutions (ALI 60 \& $120 \mu \mathrm{g} / \mathrm{ml}$; HCT $5 \& 10 \mu \mathrm{g} / \mathrm{ml}$ ) six times by measuring the absorbances of both the drug solutions at 271 and $280 \mathrm{~nm}$ for SE method; 255 and $271 \mathrm{~nm}$ for AR method; 241 and $280.20 \mathrm{~nm}$ for $1^{\text {st }}$ DR method, respectively and \% RSD was calculated. Intra-day precision was carried out by analyzing sample solutions (ALI $60 \&$ $120 \mu \mathrm{g} / \mathrm{ml}$; HCT $5 \& 10 \mu \mathrm{g} / \mathrm{ml}$ ) in triplicate at two different concentration levels for three times on the same day within the linearity range and \% RSD was calculated. Inter-day precision was determined by repeated analysis of sample solutions (ALI $60 \&$ $120 \mu \mathrm{g} / \mathrm{ml}$; HCT $5 \& 10 \mu \mathrm{g} / \mathrm{ml}$ ) in triplicate at two different concentration levels within the linearity range on three different days and percentage RSD was calculated.

\section{Accuracy}

In order to ensure the suitability and reliability of the projected methods, recovery studies were carried out by standard 


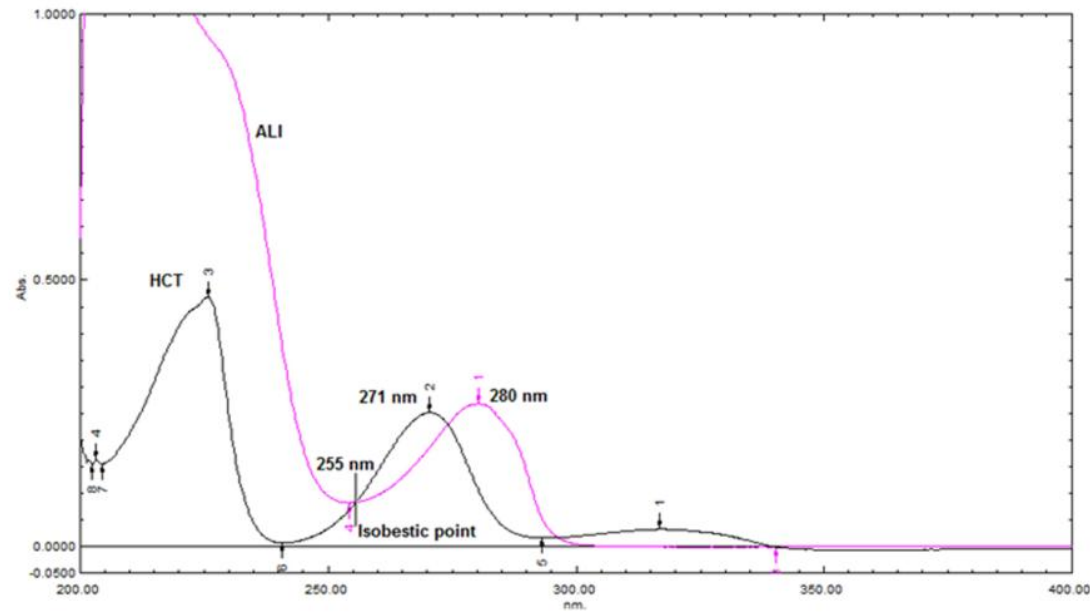

Fig. 2: Overlain UV spectra of ALI $(60 \mu \mathrm{g} / \mathrm{ml})$ and HCT $(5 \mu \mathrm{g} / \mathrm{ml})$.

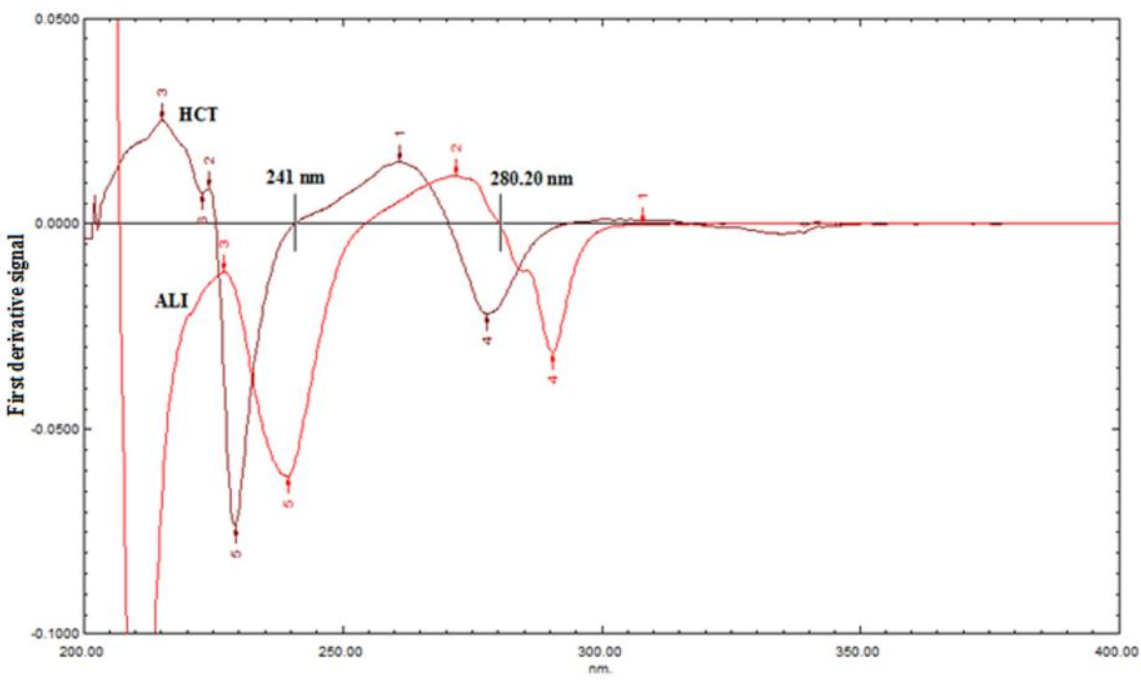

Fig. 3: Overlain $1^{\text {st }}$ derivative UV-spectra of ALI $(60 \mu \mathrm{g} / \mathrm{ml})$ and HCT $(5 \mu \mathrm{g} / \mathrm{ml})$.

Table 1: Absorptivity values for $S E$ and $A R$ method.

\begin{tabular}{|c|c|c|c|c|c|c|c|}
\hline \multicolumn{4}{|c|}{ SE } & \multicolumn{4}{|c|}{$\mathbf{A R}$} \\
\hline \multicolumn{4}{|c|}{ Avg. absorptivity* } & \multicolumn{4}{|c|}{ Avg. absorptivity* } \\
\hline \multicolumn{2}{|c|}{ ALI } & \multicolumn{2}{|c|}{ HCT } & \multicolumn{2}{|c|}{ ALI } & \multicolumn{2}{|c|}{ HCT } \\
\hline $271 \mathrm{~nm}$ & $280 \mathrm{~nm}$ & $271 \mathrm{~nm}$ & $280 \mathrm{~nm}$ & $255 \mathrm{~nm}$ & $271 \mathrm{~nm}$ & $255 \mathrm{~nm}$ & $271 \mathrm{~nm}$ \\
\hline 35.28 & 49.62 & 590.56 & 268.20 & 15.11 & 35.28 & 187.63 & 590.56 \\
\hline
\end{tabular}

$*(n=6)$ Average of six determinations.

Table 2: Summary of validation parameters for the proposed methods.

\begin{tabular}{|c|c|c|c|c|c|c|c|c|c|c|}
\hline \multirow{2}{*}{ Parameters } & \multicolumn{4}{|c|}{ SE } & \multicolumn{4}{|c|}{$\mathbf{A R}$} & \multicolumn{2}{|c|}{ DR } \\
\hline & \multicolumn{2}{|c|}{ ALI } & \multicolumn{2}{|c|}{ HCT } & \multicolumn{2}{|c|}{ ALI } & \multicolumn{2}{|c|}{ HCT } & ALI & HCT \\
\hline Wavelengths (nm) & 271 & 280 & 271 & 280 & 255 & 271 & 255 & 271 & 241 & 280.20 \\
\hline Linearity range $(\mu \mathrm{g} / \mathrm{ml})$ & \multicolumn{10}{|c|}{ ALI: 6-300; HCT : 0.5-25 } \\
\hline Correlation coefficient & 0.9998 & 0.9998 & 0.9997 & 0.9999 & 0.9995 & 0.9998 & 0.9998 & 0.9999 & 0.9992 & 0.9992 \\
\hline Regression equation & & & & & & & & & & \\
\hline Intercept & 0.0069 & 0.0036 & 0.0007 & 0.0006 & 0.0045 & 0.0069 & 0.0008 & 0.0007 & 0.0022 & 0.0004 \\
\hline Slope & 0.0036 & 0.0051 & 0.0592 & 0.0268 & 0.0016 & 0.0036 & 0.0189 & 0.0592 & 0.001 & 0.0045 \\
\hline $\operatorname{LOD}(\mu \mathrm{g} / \mathrm{ml})$ & 1.26 & 0.64 & 0.05 & 0.05 & 1.44 & 1.26 & 0.09 & 0.05 & 0.89 & 0.12 \\
\hline $\mathrm{LOQ}(\mu \mathrm{g} / \mathrm{ml})$ & 3.82 & 1.94 & 0.14 & 0.16 & 4.35 & 3.82 & 0.26 & 0.14 & 2.69 & 0.36 \\
\hline Specificity & \multicolumn{10}{|c|}{ No interference } \\
\hline Precision (\% RSD) & & & & & & & & & & \\
\hline $\begin{array}{l}\text { Repeatability of } \\
\text { measurement }(n=6)^{*}\end{array}$ & 0.61 & 0.45 & 0.72 & 0.72 & 0.61 & 0.61 & 0.61 & 0.73 & 0.82 & 1.47 \\
\hline Intra-day $(n=3)^{*}$ & 0.75 & 0.65 & 0.55 & 0.85 & 0.80 & 0.73 & 0.80 & 0.55 & 0.84 & 0.85 \\
\hline Inter-day $(\mathrm{n}=3)^{*}$ & 0.87 & 0.95 & 0.59 & 1.12 & 0.61 & 0.87 & 0.61 & 0.59 & 0.84 & 0.86 \\
\hline
\end{tabular}

$* \mathrm{n}=$ number of determinations, \% RSD (Percentage relative standard deviation). 
addition method. To an equivalent quantity of pre-analyzed sample solution (Formulation, ALI: 60, 90 and $120 \mu \mathrm{g} / \mathrm{ml}$; HCT: 5, 7.5 and $10 \mu \mathrm{g} / \mathrm{ml}$ ), a known concentration of standard ALI and HCT were added at 50, 100 and $150 \%$ level and the resulting solutions were reanalyzed by proposed methods and \% recoveries were calculated. The results of accuracy studies were assessed based on the percentage of standard ALI and HCT recovered from the formulation by using following formula:-

$\%$ Recovery

$=$ (Amount of drug found after addition of standard drug

- Amount of drug found before addition of standard drug)

/(Amount of standard drug added $) \times 100$

\section{$L O D$ and $L O Q$}

Sensitivity of the proposed methods were determined in terms of LOD and LOQ. The limit of detection and limit of quantification of ALI and HCT were calculated using following equation as per $\mathrm{ICH}$ guidelines.

$$
L O D=3.3 \times \frac{\sigma}{s} \quad L O Q=10 \times \frac{\sigma}{S}
$$

Where $\sigma=$ The standard deviation of the response, $\mathrm{S}=$ The slope of the calibration curve

\section{Stability of the Solution}

Stability of the solutions were checked by observing any changes in terms of absorbance and spectral pattern compared to freshly prepared solutions by keeping the solutions at room temperature and analyzing at a frequent interval.

\section{RESULTS AND DISCUSSION}

Three simple, sensitive, precise and accurate UVspectroscopic methods namely SE, AR and $1^{\text {st }}$ DR spectroscopic methods were developed and validated for simultaneous estimation of ALI and HCT in tablet dosage form. SE method was based on the measurement of absorbance at 271 and $280 \mathrm{~nm}$ for both the drugs. In AR method 255 and $271 \mathrm{~nm}$ was used for the detection and quantification of ALI and HCT. $1^{\text {st }}$ DR method was involved in the conversion of UV-spectra in to first derivative spectra and measurement of first derivative signal at $241 \& 280.20$ $\mathrm{nm}$ for ALI and HCT, respectively using $2 \mathrm{~nm}$ as wavelength interval $(\Delta \lambda)$ and 1 as scaling factor. Comparative overlain spectra of placebo and drug solutions indicate that there was no interference between excipients and standard drugs (Figure $4 \& 5$ ). ALI and HCT were found to be linear in the concentration range of 6-300 $\mu \mathrm{g} / \mathrm{ml}$ and $0.5-25 \mu \mathrm{g} / \mathrm{ml}$, respectively for all the methods. Calibration graphs were plotted using absorbance of standard drug versus concentration for SE and AR method. $1^{\text {st }}$ derivative signal of standard drug solution versus concentration was used to plot calibration curve for DR method. Regression analysis was performed by least square method to calculate the values of slope, intercept and correlation coefficient for ALI and HCT at respective wavelengths. Results of precision studies expressed in \% RSD follows ICH guideline acceptable limits $(<2)$, which shows good repeatability, low intra and inter-day variability, indicating an excellent precision of the developed methods (Table 2).

The results of recovery studies ranged from $97-102 \%$ for both the drugs showing the accuracy of the proposed methods (Table 3). This indicates that there was no interference from tablet excipients. The values of LOD and LOQ were found to be very low which proves the sensitivity of the proposed methods (Table 2 ). Solution stability was performed at room temperature and it was found to be stable up to two days. The proposed methods were successfully applied for the quantitative determination of ALI and HCT in commercial formulation (Rasilez $\mathrm{HCT}^{\circledR}$ tablet: $300 \mathrm{mg}$ of ALI and $25 \mathrm{mg}$ of HCT). Six replicate determinations were carried out and experimental values were found to be within 96 and $101 \%$ for both the drugs and hence the developed methods can be used for the simultaneous determination of both the drugs in combined formulation (Table 4).

Statistical analysis was performed to assess the effect of all the developed methods based on assay results obtained. Statistical significance between all the methods were tested using one-way ANOVA followed by Bonferroni multiple comparison

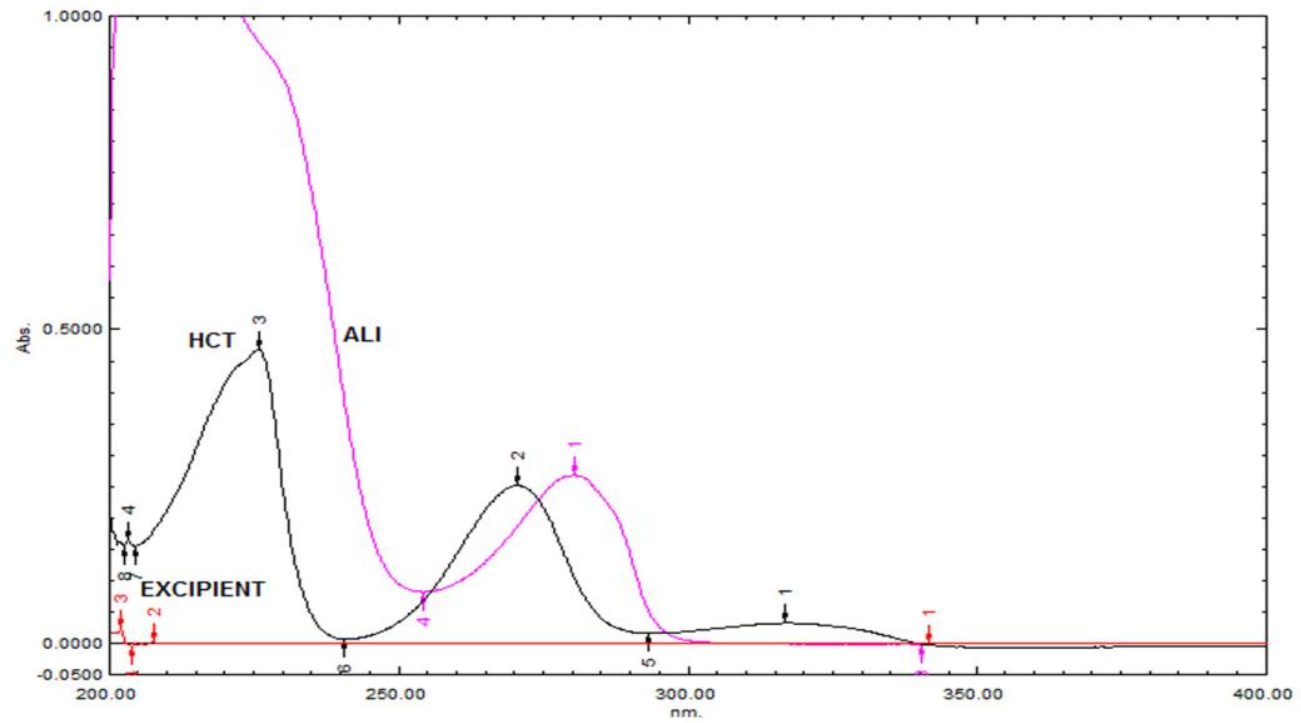

Fig. 4: Overlain UV-spectra of formulation excipients and standard drugs. 


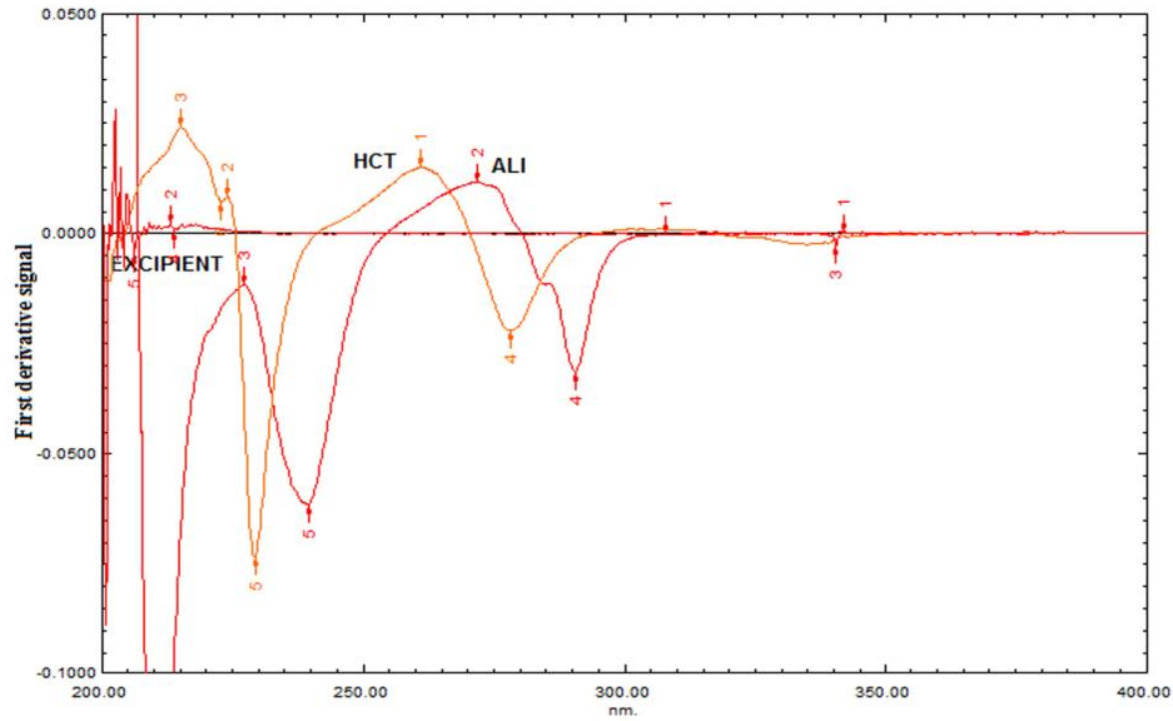

Fig. 5: Overlain first derivative UV-spectra of formulation excipients and standard drugs.

Table 3: Results of recovery studies.

\begin{tabular}{|c|c|c|c|c|c|c|c|}
\hline \multirow{2}{*}{ Drugs } & \multirow{2}{*}{ Level (\%) } & \multicolumn{3}{|c|}{ Recovery $(\%)^{*}$} & \multicolumn{3}{|c|}{ RSD (\%) } \\
\hline & & SE & $\mathbf{A R}$ & DR & SE & $\mathbf{A R}$ & DR \\
\hline \multirow{3}{*}{ ALI } & 50 & $99.71 \pm 0.47$ & $99.12 \pm 0.29$ & $100.50 \pm 1.59$ & 0.47 & 0.29 & 1.58 \\
\hline & 100 & $100.11 \pm 0.25$ & $99.55 \pm 0.80$ & $100.44 \pm 1.18$ & 0.25 & 0.81 & 1.18 \\
\hline & 150 & $99.97 \pm 0.22$ & $99.39 \pm 0.88$ & $99.11 \pm 1.78$ & 0.22 & 0.89 & 1.79 \\
\hline \multirow{3}{*}{ HCT } & 50 & $97.51 \pm 0.24$ & $99.46 \pm 0.97$ & $99.01 \pm 0.31$ & 0.24 & 0.97 & 0.31 \\
\hline & 100 & $98.23 \pm 0.26$ & $99.79 \pm 1.61$ & $100.59 \pm 1.36$ & 0.27 & 1.62 & 1.35 \\
\hline & 150 & $98.68 \pm 0.26$ & $99.94 \pm 1.63$ & $99.88 \pm 1.35$ & 0.26 & 1.64 & 1.35 \\
\hline
\end{tabular}

*Mean \pm SD ( $\mathrm{n}=3$ ), SD (Standard deviation), \% RSD (Percentage relative standard deviation).

Table 4: Results of analysis of marketed formulation using different methods.

\begin{tabular}{|c|c|c|c|c|c|c|c|c|c|c|}
\hline \multirow{2}{*}{ Drugs } & \multirow{2}{*}{$\begin{array}{c}\text { Labeled Amount } \\
\text { (mg/tab) }\end{array}$} & \multicolumn{3}{|c|}{ Amount Found (mg/tab) } & \multicolumn{3}{|c|}{ Amount Found (\%)* } & \multicolumn{3}{|c|}{ RSD (\%) } \\
\hline & & SE & $\mathbf{A R}$ & DR & SE & $\mathbf{A R}$ & DR & SE & $\mathbf{A R}$ & DR \\
\hline ALI & 300 & 296.87 & 295.29 & 295.72 & $98.96 \pm 0.82$ & $98.43 \pm 1.18$ & $98.58 \pm 1.39$ & 0.83 & 1.20 & 1.41 \\
\hline HCT & 25 & 24.70 & 24.47 & 24.48 & $98.81 \pm 1.20$ & $97.88 \pm 1.12$ & $97.93 \pm 1.12$ & 1.22 & 1.14 & 1.14 \\
\hline
\end{tabular}

*Mean \pm SD $(\mathrm{n}=6)$, SD (Standard deviation), \% RSD (Percentage relative standard deviation).

Table 5: Results of statistical comparison using one way ANOVA \& Bonferroni multiple comparison test for SE, AR and DR spectroscopic method.

\begin{tabular}{lccc}
\hline Drugs & Simultaneous Equation Method & Absorbance Ratio Method & First Derivative Method \\
\hline ALI & $98.96 \pm 0.82$ & $98.43 \pm 1.18$ & $98.58 \pm 1.34$ \\
HCT & $98.81 \pm 1.20$ & $97.88 \pm 1.12$ & $97.93 \pm 1.12$ \\
\hline
\end{tabular}

All values are expressed in Mean \pm SD $(n=6)$.

test (95\% confidence level) as appropriate using computer based fitting program (Prism, Graphpad version 5, Graphpad software Inc). Significance level was set at $\mathrm{p}<0.05$ for all the tests. Results of ANOVA are presented in Table 5. The results of assay revealed that there was no statistical significant difference between all the developed methods.

\section{CONCLUSION}

Different methods namely $\mathrm{SE}, \mathrm{AR}$ and $1^{\text {st }}$ DR spectroscopic methods were developed for simultaneous determination of ALI \& HCT in combined tablet dosage form. All the developed methods were validated as per ICH guidelines.
Proposed methods were found to be simple, sensitive, precise, accurate and cost effective. Developed methods possesses several advantages over existing methods are as follows: all the developed UV-spectrophotometric methods are very simple, requires little sample preparation procedure, wide concentration range with high sensitivity, method describes standard and sample preparation procedure based on the form of analytes under investigation, i.e. aliskiren (13.26 mg of aliskiren hemifumarate is equivalent to 12 $\mathrm{mg}$ of aliskiren). Statistical data reveals that there is no statistical significant difference between all the three methods. Therefore, all the methods can be used successfully for routine analysis of ALI and HCT in combined tablet dosage form. 


\section{ACKNOWLEDGEMENT}

Authors are thankful to the Department of Pharmacy, Sumandeep Vidyapeeth University, Piparia, Waghodia, Vadodara, Gujarat, India for providing all the facilities to carry out the project work.

\section{REFERENCES}

Martindale, The complete drug reference. $36^{\text {th }}$ Edition. Vol. I. London (UK): Pharmaceutical Press (An Imprint of RPS Publishing); 2009; 1206-1207, 1310.

The Merck Index, Merck \& Co Inc, White House Station, New Jersey, USA, $13^{\text {th }}$ Edition, 2001,854.

Indian Pharmacopoeia, Government of India, Ministry of Health \& Family Welfare, Volume-2, Ghaziabad, The Indian Pharmacopoeia Commission, 2007;1194-96.

Sen AK, Sen DB, Maheshwari RM, Balaraman R, Seth AK. Quantitative simultaneous determination of aliskiren hemifumarate and hydrochlorothiazide in combined tablet formulation by RP-HPLC. International Journal of Pharmacy and Pharmaceutical Sciences, 2015;7(8):142-5.

Ezzeldin MI, Shokry E, Fouad MA, Elbagary RI. Application of chromatographic and spectrophotometric methods for the analysis of aliskiren and hydrochlorothiazide antihypertensive combination. International Journal of Advanced Chemistry, 2013;1(2):13-20.

Ezzeldin MI, Shokry E, Fouad MA, Elbagary RI. Application of chromatographic and spectrophotometric methods for the analysis of selected antihypertensive combinations. International Journal of Analytical, Pharmaceutical \& Biomedical Sciences, 2013;2(3):6-15.

Patel SR, Patel CN. Development and validation of spectrophotometric method for determination of aliskiren, amlodipine and hydrochlorothiazide in combined pharmaceutical dosage forms. Asian Journal of Pharmaceutical Analysis, 2014; 4(4):162-7.

Sangoi MS, Sangoi MW, Oliveira PR, Todeschini V, Rolim CMB. Rapid simultaneous determination of aliskiren and hydrochlorothiazide from their pharmaceutical formulations by monolithic silica HPLC column employing experimental designs. Journal of Liquid Chromatography \& Related Technologies, 2011;34(17):1976-96.

Karvelis D, Kalogria E, Panderi I. A stability-indicating HPLC method for the quantification of aliskiren and hydrochlorothiazide in a pharmaceutical formulation. Journal of AOAC International, 2014;97(6):1519-25.

Belal F, Walash M, El-Enany N, Zayed S. Simultaneous determination of aliskiren and hydrochlorothiazide in tablets and spiked human urine by ion-pair liquid chromatography. Die Pharmazie, 2013;68(12):933-8.

Dimitrios K, Eleni K, Irene P. A stability indicating HPLC method for the quantification of aliskiren and hydrochlorothiazide in a pharmaceutical formulation. Journal of AOAC International, 2014; 97(6): 1519-25.
Swamy GK, Sravanthi P, Surekha ML, Kumar JMR, Rao JVLNS. Validated RP-HPLC method for the simultaneous determination of aliskiren, hydrochlorothiazide and amlodipine besylate in bulk and pharmaceutical formulations. International Journal of ChemTech Research, 2012;4(4):1666-73.

Sangoi MS, Wrasse-Sangoi M, Oliveira PR, Rolim CMB, Steppe M. Simultaneous determination of aliskiren and hydrochlorothiazide from their pharmaceutical preparations using a validated stability-indicating MEKC method. Journal of Separation Science, 2011;34(15):1859-66.

Salim MM, Ebeid WM, El-Enany N, Belal F, Walash M, Patonay G. Simultaneous determination of aliskiren hemifumarate, amlodipine besylate and hydrochlorothiazide in their triple mixture dosage form by capillary zone electrophoresis. Journal of Separation Science, 2014;37(9-10):1206-13.

Beckett AH, Stenlake JB. Instrumental methods in the development and use of medicines. In, practical pharmaceutical chemistry (Part-2), $4^{\text {th }}$ edition. New Delhi, CBS Publishers and Distributors, 2005;13,275-99.

Sen DB, Sen AK, Zanwar A, Balaraman R, Seth AK. Determination of alogliptin benzoate and metformin hydrochloride in tablet dosage form by simultaneous equation and absorption ratio method. International Journal of Pharmacy and Pharmaceutical Sciences, 2015;7(8):380-83.

International Conference on Harmonization (ICH). Validation of Analytical Procedures: Text and Methodology Q2(R1). Geneva; 2005.

\section{How to cite this article:}

Sen AK, Sen DB, Maheshwari RA, Balaraman R, Seth AK. Simultaneous estimation of Aliskiren hemifumarate and Hydrochlorothiazide in combined Tablet Formulation by Simultaneous equation, Absorbance ratio and First derivative Spectroscopic Methods. J App Pharm Sci, 2016; 6 (07): 164-170. 